\title{
The families are marching in. Be prepared!
}

\author{
HEINZ KATSCHNIG
}

I remember vividly, when a couple of years ago at an Annual Meeting of the American Psychiatric Association in a large New York hotel suddenly the lights went down. The uncertainty among the hundreds of attenders of a symposium on the treatment of schizophrenia lasted only seconds. The lights went on quickly and in had marched some twenty or thirty members of the National Alliance of the Mentally Ill (NAMI), an advocacy group for psychiatric patients formed mainly by their family members. Their hammering rhyme "Clozapine is priced obscene» still resonates in my ear. I was angry at the time, since I had been keen to listen to a lecture by John Strauss on the patient's role in coping with schizophrenia. In retrospect the relatives were successful. Reportedly, the price for Clozapine, an in the USA then new and expensive atypical neuroleptic, has fallen.

The incident can serve to illustrate three points: (1) the relatives of psychiatric patients are there and they are potentially powerful in fighting for their and their patients' interests; (2) their presence and way of behaving may create anger in us professionals; and (3) there is a third party, the patients, who are still marginal (incidentally a lecture on their role was disturbed), but who have interests of their own which are different from those of the professionals and of the relatives.

On the political level relatives and family members of the mentally ill have been around since quite a time - the first self-help associations were founded in France in 1964 (UNAFAM - Union Nationale des Amis et des Familles des Malades Mentaux), in England in 1971 (NSF - National

Indirizzo per la corrispondenza: Prof. H. Katschnig, Department of Psychiatry, University of Vienna, Währingergürtel 18-20, 2 - 1090 Vienna (Austria).

Fax. (+43) 1-40400-3605.
Schizophrenia Fellowship), in Austria in 1977 (HPE - Hilfe für Angehörige Psychisch Erkrankter) and in 1978 in the USA (NAMI - National Alliance for the Mentally Ill). Relatives cannot be ignored anymore as a political lobby and pressure group. However, the systematic involvement of relatives into the daily management of mental disorder is not only underdeveloped, there is even reluctance among staff to cooperate with relatives (Baker et al., 1995).

But the days of the old mental hospital, when psychiatrists and nurses played the exclusive role in caring for psychiatric patients are over (Stanton \& Schwartz, 1954; Belknap, 1956). Since patients have returned into the community not only the number of types of professionals has increased, but the family members who often care for their patients and have become experts in their own right, are also there. Also the spectrum of problems to be dealt with has broadened: handling money, alcohol problems, suicide threats, family conflicts, rejection by neighbours and other problems make the field so much more complicated today than it had been in the old days. And professionals are not prepared for that type of problems.

\section{WHY TO INVOLVE RELATIVES INTO COPING WITH MENTAL ILLNESS}

Most patients do have a family at the time of the onset of their illness. But they are often rejected, left alone or leave their families themselves because of conflicts. In the long run they often find themselves in isolation. Such loneliness is very often the result of not paying appropriate attention to the patient's family and of not supporting it in its efforts to cope with the patient's illness. 
It is my experience that family members, despite or even because of being burdened (Grad \& Sainsbury, 1968), are experts for living with a psychiatric patient in the community. With some help from benevolent professionals they can provide a safety net for patients who often have become unattractive and rejected members of society (Katschnig \& Konieczna, 1989).

Of course, every professional knows examples of families where the safety net has turned into a «spider web», preventing the patient from becoming autonomous. It seems that such single negative experiences are used by many professionals as an excuse for not exposing themselves to family members of the psychiatric patient. Such exposure often creates discomfort, since relatives tend to be critical of our services and our behaviour and often have opinions which seem strange to us.

\section{TRADITIONAL AND NEW ROLES OF FAMILY MEMBERS OF THE MENTALLY ILL}

Family members, especially parents, of mentally ill patients usually find themselves placed by mental health professionals into one or more of four different roles (Katschnig et al., 1985): (1) they serve as objects of genetic studies; (2) they are used as informants about the patient's illness; (3) they are regarded as the cause of their family member's mental illness by some psychiatric theoreticians and practitioners; and, finally (4) they may be regarded as victims of the mental illness of their children. All these roles are marginal and unsatisfying. Until recently, this marginality has been reflected in the fact that relatives of psychiatric patients were not actively involved in the management of mental illness and were excluded from planning processes.

In many countries the formation of self-help organisations has changed the situation dramatically over the last twenty years. These associations speak for themselves and for their own interest (Katschnig \& Konieczna, 1987). This is a most valuable and wanted aspect of their activities, since this emphasis has created a new type of relative, whom we increasingly meet in our services: A relative who is an active participant in the process of coping with mental illness and who contributes his ideas and energy to solving the many problems accompanying mental illness, a relative who is not a passive recipient of professional advise but a member of a problem solving group (Falloon et al., 1984).

\section{COOPERATING WITH FAMILY MEMBERS OF THE MENTALLY ILL: HOW TO DO IT}

Before thinking about how to cooperate with family members of the mentally ill, one has to acknowledge that the interests of the professionals do not necessarily coincide with the interests of family members of the mentally ill. It is well known that many institutions mainly serve their own interests. Since, by definition, services have to serve the consumers, mechanisms have to be established which allow feedback to the services about the extent to which they qualitatively and quantitatively meet the needs of patients and their families. Also, mechanisms of participation and decision making seem necessary, since feedback might not be enough.

We have been working in Vienna since 15 years with relatives on the level of services (Katschnig, 1989). Over the years we have developed a couple of principles which can serve as a guideline for cooperating with relatives (Katschnig \& Konieczna, 1989). The main principle is that the relatives' competence, autonomy and self-confidence has to grow in order for them to become potent partners in fighting mental illness. Two «techniques» have proven to be useful in achieving that goal: (1) partially giving up the traditional role of the expert, and (2) working with relatives in groups.

The first «technique» implies that the traditional asymmetrical relationship with a «knowledgeable» and active professional and a passive relative is given up. In fact, professionals do not know that much, and making this clear to relatives, while in the beginning increasing their anxiety, opens the door to an active and creative participation of the relatives in solving problems. Rogers (1957) coined the formula of "unconditional positive regard» for the patient in a therapeutic relationship, and the same should apply to the relationship between professionals and relatives. The relative should not only get the feeling that he is an expert in his own right, he should be that expert.

The second «technique» is working with groups of relatives instead of with single relatives, i.e. letting them be together with other relatives while we work with them. Being together with someone who 
has a similar problem increases confidence. A group setting not only offers the emotional experience of not being alone but also the possibility of getting advice from «peer experts». Also, the possibility to help other group members is an important aspect of becoming more self-confident.

Wherever I have worked in the last 15 years or so, I have insisted that staff organises weekly groups with the relatives of the patients. Preferably such groups take place in the early evening, when working relatives are able to attend. They usually last for one hour or one hour and a half and are coordinated by two professionals, usually a male and a female staff member, preferably a doctor and a non-doctor. Such work with relatives in groups is midway on the spectrum between pure professional help (as is the case in classical family therapy) and pure self-help (as it is provided by relatives' self-help associations). My experience is that such groups are not only helpful for the families but in the long run also for professionals, although they may first create discomfort for them. Such groups are most profitable for families of patients with a medium duration of illness. If illness duration has been too short, family members might not yet be willing to identify themselves as relatives of a psychiatric patient and will not attend such groups; when illness duration has been too long, resignation might prevent relatives from coming.

We have experimented with different forms of cooperation with relatives. Starting from the "patient centered» groups just described, we have come to groups which are organised outside services, where family members tend to be more critical, since they have nothing to fear about sanctions against their patients.

We have also developed a more complex residential model for working with relatives, the «Pension Bettina» in Vienna (Katschnig et al. 1989). Here, 10 schizophrenic patients live together in a group home for 17 months, and relatives come in to stay with them for a couple of hours each week and join in running the place, make night duties once a month and act as partners for the patients, not only for their own patient. On weekends we are closed and families are together at home. We have coined the metaphor of "Pension Bettina» as a stage, where new behaviours can be learned and rehearsed. This framework provides the possibility that a schizophrenic patient interacts with the father or mother of another patient and vice versa. In this way the peculiarities of the disease can be better understood, since biographical conflicts, which often prevent a clear sight on the disease problems, are not present.

Some 50 families have so far completed this «school of living», where, on a neutral territory during a neutral time of 17 months, professionals, family members and patients learn how to survive despite dissent and to find out where they can agree. The number of days in hospital has fallen dramatically after the end of the programme, if compared to the same time before. It is interesting to see that after the 17 months are over, families tend to stay together, hire apartments to create group homes for the patients and continue to assist these patients and each other while remaining in the background.

\section{CONCLUSION}

There is no chance of escape - the families are coming and every professional should be prepared. The families are marching in, as the recent foundation of a European Federation of Associations of Families of Mentally Ill People (EUFAMI) shows. There are bright, less bright and difficult professionals, and there are bright, less bright and difficult family members of the mentally ill. We should be glad, they are coming and we should welcome them. There will be consent and dissent, and comfort and discomfort. But a culture of discussion and cooperation is necessary in order to make the best out of the valuable experiences of relatives who live together with their sick family members. Cooperating with relatives might be uncomfortable at first sight, but it can be an important «anti-burnout» mechanism for us professionals. And there is more to come - the patients are already forming their own self-help organisations and there will soon be a necessity for a next article entitled «The patients are marching in».

\section{REFERENCES}

Baker B.L., Heller T.L., Blacher J. \& Pfeiffer S.I. (1995). Staff attitudes toward family involvement in residential treatment centers for children. Psychiatric Services 46, 60-65.

Belknap I. (1956). Human Problems of a State Mental Hospital. McGraw-Hill: New York.

Falloon I.R.H., Boyd J.L. \& McGill C.W. (ed.) (1984). Family 
Care of Schizophrenia. A Problem-Solving Approach to the Treatment of Mental Illness. Guildford Press: New York.

Grad J. \& Sainsbury E. (1968). The effect that patients have on their families in a community care and a control psychiatric service. A two years follow-up. British Journal of Psychiatry $114,265-278$

Katschnig H. (1989). Die andere Seite der Schizophrenie - Patienten zu Hause. 3. erw. Auflage. Psychologie Verlags Union: München.

Katschnig H., Konieczna T. \& Sint P. (1985). Helping families of schizophrenic patients: Professionally supported self help. In: Pichot P., P. Berner R., Wolf K. Thau (eds.): Psychiatry the State of the Art. Volume 7. Proceedings of the 7th World Congress of Psychiatry, Vienna, 1983. Plenum Publishing Corporation, New York, pp.487-494.

Katschnig H. \& Konieczna T. (1987). The philosophy and practice of self-help for relatives of the mentally ill. In Psychosocial
Treatment of Schizophrenia: Multialimensional Concepts, Psychological, Family and Self-Help Perspectives (ed. J.S. Strauss W., Böker \& H.D. Brenner), pp.191-200. Hans Huber Publishers: Toronto.

Katschnig H. \& Konieczna T. (1989). What works in work with relatives? - A hypothesis. British Journal of Psychiatry 155, 144-150.

Katschnig H., Konieczna T., Michelbach H. \& Sint P. (1989). Intimität auf Distanz - ein familienorientiertes Wohnheim für schizophrene Patienten. In Die andere Seite der Schizophrenie - Patienten zu Hause. 3. erw. Auflage. (ed. H.Katschnig). pp. 229-242. Psychologie Verlags Union: München.

Rogers, C.R. (1957). The necessary and sufficient conditions of therapeutic personality changes. Journal of Consulting Psychology 21, 95-103.

Stanton A. \& Schwartz M. (1954). The Mental Hospital. Basic Books: New York. 